\section{Democracia: entre a igualdade e o egoísmo}

\section{Democracy: between equality and egoism}

DUNN, John. A história da democracia: um ensaio sobre a libertação do povo. Tradução de Bruno Gambarotto. São Paulo, Editora da Unifesp, 2016. 296 páginas.

\section{Roger Gustavo Manenti Laureano}

Doutorando em sociologia política da Universidade Federal de Santa Catarina (UFSC) e bolsista da Capes. E-mail: <rogergmlaureano@gmail.com>.

DOI: $10.1590 / 339815 / 2018$

Nos últimos três séculos, a democracia deixou de ser uma palavra qualquer proveniente do vocabulário grego para se tornar um valor político quase universal. O "democrata", de origem muito mais recente, deixou de ser um adjetivo exclusivamente pejorativo e se tornou símbolo de virtude moral. Como isso aconteceu? Talvez essa história já tenha sido contada inúmeras vezes, de maneira que nada de surpreendentemente novo possamos encontrar em uma nova arqueologia dos acontecimentos. Mas John Dunn, um dos célebres nomes daquela que ficou conhecida como Escola de Cambridge, oferece-nos uma nova abordagem. O historiador britânico é mais popular por suas obras acerca do pensamento político de Locke, clássico do qual é uma incontestável autoridade. Essa não é, contudo, a sua primeira empreitada no tema, é apenas a de maior fôlego, a única que se propôs uma narrativa diacrônica que parte de Atenas até os nossos tempos. Em A história da democracia..., Dunn apresenta uma narrativa tripartite de seu objeto: a democracia como conceito, como ideia, e como um conjunto de práticas. Ao contrário do que o título possa indicar à primeira vista, a história não é construída com a finalidade de consagrar a democracia, mas de compreender como ela veio a se tornar, contemporaneamente, a única fonte possível de legitimidade política no mundo ocidental.

O livro de John Dunn é introduzido com muitas perguntas e o autor náo se propóe a responder todas elas. Duas, no entanto, tocam no ponto primordial de seu argumento: (1) por que, pela primeira vez em nossa história, há um único nome (democracia) "de alcance global para designar a base legítima da autoridade política?” (p. 27) e (2) por que essa forma de Estado, "a democracia representativa capitalista moderna, por ora vence a luta global por riqueza e poder?” (p. 34). A resposta, no entanto, principia-se nas origens do conceito.

Não podemos afirmar que o modelo político institucional que chamamos de democracia tenha, de fato, nascido em Atenas no século VI a.C., mas foi certamente naquela regiáo da Grécia que a palavra que usamos para descrever esse modelo foi cunhada pela primeira vez: demokratia, o governo do demos (povo). Junto dela, nasceram seus primeiros detratores, como Platão e Aristóteles. É apenas na História da Guerra do Peloponeso, de Tucídides, que encontramos em um dos protagonistas dessa narrativa, Péricles, uma entusiasta voz defensora do modelo democrático ateniense. Seu discurso pode ser visto como uma consagraçáo de Atenas e todos que se sacrificaram pela cidade. Não há indivíduos em suas linhas, ou feitos heroicos nomeados; o verdadeiro objeto de sua glorificação é a própria comunidade e seu sistema democrático, com uma vida pública ativa. Nas palavras de Péricles, se eternizam algumas características que logo marcariam a democracia junto de seus valores coletivos. "Pois olhamos o homem alheio às atividades públicas", aponta o Péricles narrado por Tucídides, "não como alguém que cuida apenas de seus próprios interesses, mas como um inútil". Retirado o indivíduo egoísta da esfera do discurso, Péricles passa a se referir ao coletivo como "nós, cidadãos atenienses" - ou seja, em tom de igualdade -, que "decidimos as questōes públicas por nós mesmos", na crença "de que não é o debate que é empecilho à ação, e sim o fato de não se estar esclarecido pelo debate" (Tucídides, 2001, p. 110). A participação na arena pública aparece como valor máximo da cultura política ateniense.

A oração fúnebre de Péricles possui, para John Dunn, duas vias interpretativas importantes para história que ele pretende narrar. Primeiramente, representa um modo de vida, baseado primordialmente em uma virtude política, que busca uma 
combinação de "comprometimento pessoal em relação à comunidade de nascimento" e "uma prática contínua de vigilante julgamento público" (Dunn, 2016, p. 42). Por outro lado, também é seguramente uma "performance diligentemente facciosa e bastante política”, cunhando a maneira pela qual os atenienses "vieram a desejar conceber a si mesmos como comunidade" (p. 43). Desejar é a palavra certa porque Péricles profere uma descrição tão cativada de sua comunidade que certamente entrava em conflito com a realidade, e que muitos atenienses isto a história nos legou - divergiam frontalmente.

Esse era o caso do Velho Oligarca, autor de A Constituição de Atenas. Seu livro se dedicava a uma crítica voraz das democracias por dar lugar aos pobres, aos marginalizados e aos mais vulgares cidadãos da comunidade. Igualmente, na clássica tipologia das formas de governo elaborada por Aristóteles em $A$ politica, a democracia é apresentada como uma forma injusta de governar a polis. Em uma visão aristotélica, isso é análogo a afirmar que sua finalidade não era o bem comum de toda a comunidade, mas apenas da população mais pobre. Porém, é em $A$ república, de Platão, que encontramos o caráter central do modelo democrático da Antiguidade que Dunn deseja destacar. Centrando-se na capacidade de ordem e governo dos modelos constitucionais existentes, e na crença de que a democracia não supre adequadamente nenhum dos dois critérios, Platão apresenta uma dupla de valores centrais para a forma de governo ateniense: a liberdade e, principalmente, a igualdade. Os homens, portanto, passam a julgar sob valores igualitários até mesmo os desiguais, e consideram todos os prazeres como idênticos, inclusive os viciosos (Platão, 2001, p. 391). A liberdade e a igualdade em excesso levariam à destruição dos vínculos sociais mais importantes para a manutenção da ordem, arrastando a cidade ao caos e à tirania - "uma queda aguda da democracia, das alturas da liberdade à mais dura e ampla servidão" (Dunn, 2016, p. 89).

As raízes desse modo igualitário de pensar podem ser encontradas na própria fundação da democracia ateniense, surgida justamente do conflito entre ricos proprietários de terra e famílias de cidadãos pobres. Mas o que é, para Platão, o ensejo de seu fracasso, outros, como Péricles, expóem orgu- lhosamente: "usamos a riqueza mais como uma oportunidade para agir que como um motivo de vanglória; entre nós não há vergonha na pobreza, mas a maior vergonha é não fazer o possível para evitá-la” (Tucídides, 2001, p. 110). Esse é o ponto primordial de John Dunn na primeira parte de sua narrativa: a igualdade como valor cardinal da democracia. E isso foi para os atenienses motivo de orgulho e repulsa.

A despeito de sua popularidade no mundo atual, a palavra demokratia foi latinizada apenas em 1260, quando Guilherme de Moerbeke traduziu a Política, de Aristóteles. Os pensadores europeus logo trataram de evitá-la; a democracia era tumultuosa, violenta e imoral, gerando uma enorme reprodução dos argumentos aristotélicos contra o governo de Atenas. Quando muito, ela era valorizada apenas como um dos elementos da Constituição mista, tida por alto valor entre os humanistas cívicos italianos. A pergunta que John Dunn se coloca, portanto, é: por que mudamos de ideia nos últimos séculos?

Uma possível virada interpretativa seria a Revolução Americana e os Federalist Papers que a seguiram. Mas o que encontramos em um dos artigos mais populares, o de número 10 , escrito por James Madison, é a democracia sendo apresentada como o "espetáculo da dissensão e da desordem" (Madison, Hamilton e Jay, 2003, p. 64), produzindo apenas alta violência e morte institucional prematura. No que se segue, Madison expóe o governo representativo republicano como uma oposição viável e superior ao governo democrático. Os fundadores dos Estados Unidos da América não se viam como sucessores de Atenas. Em grande medida, suas considerações sobre os sistemas democráticos não se diferenciavam substancialmente da visão pejorativa até então vigente. Mesmo no fim de sua vida, quando os Estados Unidos já eram amplamente reconhecidos como um regime democrático - com o auxílio de Tocqueville -, "Madison mostra pouco entusiasmo pelo termo" (Dunn, 2016, p. 123).

É na Revolução Francesa que se encontra a real mudança. Rosanvallon (1995, p. 146) já havia identificado na eloquente figura de Robespierre a guinada que inseriu as noçóes de república e representação no conceito de democracia, definindo-a como "um estado em que o povo é soberano, guia- 
do por leis que são sua obra, faz ele mesmo tudo o que pode fazer, e através de delegados faz tudo aquilo que não pode fazer por si só (Robespierre, 1999 , p. 144, grifo nosso). Unindo república, representação e democracia como partes integrantes de uma mesma concepção política, em Robespierre, pela primeira vez na modernidade, "a democracia finalmente surge não meramente como expressão passageira de gosto político", mas, de maneira organizada, como "uma visão integral de política" (Dunn, 2016, p. 166). As palavras do revolucionário francês, dada a importância global dos eventos em que foi protagonista, mudaram de maneira radical a história do conceito, esvaziando-o de seu elemento institucional clássico - a participação direta do povo na arena pública -, e diminuindo o peso da igualdade que tanto assombrou os filósofos da Antiguidade. A ruptura realizada por Robespierre demonstra uma ampla conexão entre o conceito e a prática da democracia; uma vez imputada a importância dos delegados na prática democrática, sua própria definição se modificou, dando prioridade a outros valores que não o da igualdade. Isso logo geraria contestação.

Os principais adversários internos da visão de Robespierre se encontravam na Conspiração dos Iguais, que tentou tomar o poder da França em 1796, ensejando o conflito que viria a marcar o futuro do conceito. Buonarroti e Babeuf são as duas figuras centrais desse movimento, que se considerava o verdadeiro defensor da igualdade em oposição à "ordem do egoísmo" ${ }^{1}$ que havia domado a cabeça da revolução, referindo-se aos líderes que se renderam aos "economistas ingleses". São nos relatos de Buonarroti que o rótulo "democrata" aparece de maneira partidária, para descrever a si mesmo e sua facção. A igualdade aqui não se restringe àquela que Tocqueville veio a narrar nos Estados Unidos da América, mas também no que dizia respeito às riquezas econômicas. "Para Babeuf e Buonarroti", aponta Dunn, "o fundamental na democracia era tão somente realizar tal ampla igualdade, a única condição incorruptível e verdadeira na qual os seres humanos poderiam viver juntos uns com os outros em qualquer escala substancial” (p. 186). A Conspiração dos Iguais, nesse sentido, mantinha-se mais fiel ao antigo significado do conceito de democracia, tendo a igualdade como seu valor supremo. Contudo, com o subsequente triunfo do capitalismo e a consolidação semântica da democracia como um tipo de governo representativo, Dunn não titubeia em declarar a vitória da ordem do egoísmo.

Dessa dupla de valores, surge o maior conflito contemporâneo em torno do conceito de democracia. É evidente que, para os Iguais, a captura da palavra foi interpretada como um roubo "descarado". Mas por que os partidários da ordem do egoísmo se preocupariam em "capturar" o conceito? Mesmo nos dias de hoje, nenhum partidário dessa vertente deixa de abraçar a democracia seriamente. "Os líderes políticos do incrível avanço capitalista”, afirma Dunn, "não têm brincado de modo irresponsável com símbolos vazios" (p. 193). A democracia lhes rendeu um amplo espaço de poder político, e conseguiram conquistá-lo com sucesso.

A narrativa não se prende a uma dicotomia maniqueísta. Não temos de um lado os heróis ortodoxos da igualdade democrática e, de outro, meros egoístas usurpadores. $\mathrm{O}$ mercado, à maneira dos economistas ingleses, é apresentado como "o mais poderoso mecanismo de desmanche da igualdade que os humanos jamais conceberam" (Dunn, 2016, p. 196). No entanto, concomitantemente, a vitória da democracia dos egoístas representou um subsequente "colapso das exclusóes", sempre de maneira envergonhada, da qual a emancipação política das mulheres é a mais recente. Em oposiçóes aos regimes repressivos, a democracia representativa se mostrou um campo mais próspero à disputa pelo reconhecimento, pois seu conteúdo "está sempre aberto à reinterpretação" (Dunn, 2016, p.208). A arena democrática se torna um campo de aspiração e de batalha. O mundo que Babeuf sonhou, por outro lado, em um sistema democrático e livre dos ricos, nunca se consolidou, nem sob as posteriores bandeiras do socialismo. Antes de outubro de 1917, todo socialista carregava de alguma maneira um valor democrático, ainda que distinto daquele que se instituiu. Com o estabelecimento do regime soviético, o mundo socialista se dividiu entre os que o rejeitavam por sua "tirania e opressão" e os que o consideravam "o verdadeiro portador da chama da igualdade", de maneira que os sociais-democratas eram taxados, não raro, como os "lacaios dos ricos" (Dunn, 2016, p. 221). 
A ruptura entre a igualdade e a democracia consolidou o "sequestro" realizado pela ordem do egoísmo, principalmente após a Segunda Guerra Mundial. Foi nessa batalha, expondo os terrores do Terceiro Reich e dos invasores japoneses na Ásia, que "os povos ameaçados e largamente dominados da Europa uniram-se à América sob a bandeira de democracia" (Dunn, 2016, p. 219). O sistema representativo foi imposto aos perdedores. Apenas a União Soviética e seus aliados se perpetuaram como resistência à ordem do egoísmo, até 1991, quando ficou inequívoco que um lado havia perdido. Da aliança bem-sucedida com a ordem do egoísmo e com a exposição dos crimes de suas possíveis alternativas, a democracia se estabelece como fonte hegemônica de legitimidade quase que por exclusão.

Durante o século XX, as próprias ideias acerca do sistema democrático foram se tornando cada vez mais minimalistas - e aqui Dunn pode nos oferecer uma interessante chave analítica da teoria democrática contemporânea. Schumpeter é o representante paradigmático desse movimento em que a democracia é apresentada como um método: "um sistema institucional para a tomada de decisóes políticas, no qual o indivíduo adquire poder de decidir mediante uma luta competitiva pelo voto do eleitor" (Schumpeter, 1961, p. 328). No mundo democrático schumpteriano, o sistema se limita a uma competição entre elites políticas pelo controle do governo. As analogias com o mercado demonstram efetivamente a vitória da ordem do egoísmo; o eleitor é um consumidor, as políticas são os produtos, e os políticos são empresários. A glória heroica que permeava figuras atenienses, como Péricles, não passam de uma sombra bruxuleante do passado da democracia. No mundo de hoje, os empreendedores eleitorais veem-se cada vez mais midiatizados em um mundo desencantado. Figuras televisivas como Trump, nos Estados Unidos, e celebridades, como jogadores de futebol, no Brasil, representam um ajuste do sistema em busca de oportunidades de reencantamento, nunca devidamente conquistado. Como aponta Dunn (p. 255), "é um mundo no qual fé, deferência e até lealdade passaram longe, e a mais profunda admiração pessoal raramente dura muito tempo". Os ideais democráticos clássicos sofrem, com Schumpeter, seu golpe final. A igualdade é decisivamente excluída do conceito - como a própria ideia de bem comum -, e este se vê definido inteiramente pela sua própria prática. A mutação conceitual é consciente, desenvolvida logo após uma crítica incisiva àquilo que o autor denominou "doutrina clássica da democracia", destinada a filósofos como Rousseau e J. S. Mill.

$\mathrm{Na}$ ciência política, a ordem do egoísmo foi representada por Schumpeter e por outros herdeiros de suas ideias minimalistas de democracia, como Dahl e Sartori. Por outro lado, vista para além de suas estruturas institucionais de seleçáo de elites, a democracia como valor político pode ainda ser uma ótima arma para a ordem dos Iguais. O verbo "democratizar" é uma voz de ruptura no sentido de eliminação dos mais diversos privilégios em esferas não diretamente ligadas ao Estado (família, sexo, comida etc.). Embora Dunn assinale a democratização de tudo que é humano como sendo "tão ilusória como promessa quanto vá como ameaça”, ele credita a essa ideia um enorme poder de atração, capaz de expandir alguns limites impostos pelo atual sistema político. Teóricos como Habermas e Pateman se encaixariam como representantes dos Iguais no mundo contemporâneo. A ordem do egoísmo reage mais drasticamente a algumas dessas proposiçóes, mas é, "na melhor das hipóteses, neutra e, na pior, absolutamente indiferente" (p. 248). No fim das contas, o dinheiro se mantém no poder, e o indivíduos, mesmo capazes de malear sua vida de maneiras muito diferentes, não superam "o princípio estruturante fundamental da forma na qual vivem” (Dunn, 2016, p. 248).

Na prática, a democracia é capaz de conceder à população maior equidade no tratamento individual, mas jamais um idêntico poder de defender os seus próprios interesses, em razão da desigualdade definida pela ordem do egoísmo. Dunn não concede um futuro melhor à proposta democrática dos herdeiros de Babeuf e Buonarrotti. A história não deixa espaço para a glória democrática. $\mathrm{O}$ que se vê nos empreendedores eleitorais não é o governo "exercido pelo povo". Fosse de fato, talvez até estivéssemos em situação pior. No final um tanto quanto melancólico, Dunn aponta a defesa menos ambiciosa da democracia como a melhor. Não se trata de justiça. "A ideia de justiça e a ideia de democracia”, ele assinala, "combinam-se de forma muito precária", constan- 
temente conflitivas entre si (Dunn, 2016, pp. 209210). O que a democracia oferece aos seus habitantes é "o fundamento mais seguro e menos pessoalmente ofensivo para vivermos juntos com nossos companheiros cidadãos dentro de nossos próprios Estados" (p. 256). Talvez nem precisasse do nome que tem, salvo algum vínculo que possui com o povo. Gabriel Cohn, no prefácio da edição brasileira do livro de Dunn, aponta o tom crítico do livro como "coisa de simpatizante exigente" (Cohn, 2016, p. 12). E é verdade, mas também é mais do que isso. John Dunn busca retirar os cientistas sociais e os filósofos das amarras do termo democracia. Em Breaking democracy's spell (Dunn, 2014), ela é apresentada como um feitiço do mundo político contemporâneo. A democracia conquistou o monopólio global da legitimidade, mas também do imaginário teórico. Não se trata, no ponto de vista de Dunn, de retornar ao antigo regime, mas de quebrar esse feitiço, pois se tornou urgente identificar onde "a democracia como ideia política ainda pode nos ajudar" e "onde ela pode apenas aprofundar a nossa confusão" (Dunn, 2014, p. 143, tradução nossa).

\section{Nota}

1 Que poderia com facilidade ser classificada como liberalismo, mas optamos por manter a nomenclatura cunhada por Bunarroti e conservada por John Dunn.
ROBESPIERRE, M. (1999), Discursos e relatórios na Convenção. Rio de Janeiro, Eduerj/Contraponto.

ROSANVALLON, P. (1995), "The history of the word democracy in France". Journal of Democracy, 6 (4): 140-154.

SCHUMPETER, J. (1961), Capitalismo, socialismo e democracia. Tradução de Ruy Jungmann. Rio de Janeiro, Fundo de Cultura.

TUCÍDIDES. (2001), História da Guerra do Peloponeso. Tradução de Mário da Gama Kury. Brasília, Editora da UnB.

\section{BIBLIOGRAFIA}

COHN, G. (2016), Prefácio, in J. Dunn, $A$ história da democracia: um ensaio sobre a libertação dos povos, São Paulo, Ed. Unifesp.

DUNN, J. (2014), Breaking democracy's spell. Nova York, Yale University Press.

MADISON, J.; HAMILTON, A. \& JAY, J. (2003), O federalista. Tradução de Hiltomar Oliveira. Belo Horizonte, Líder.

PLATÃO. (2001), A república. Tradução de Maria Helena Pereira. Lisboa, Fundação Calouste Gulbenkian. 